\title{
Field Screening of Seven Cultivars of Cabbage Against Cabbage Butterfly (Pieris brassicae) and Cabbage Aphids (Brevicoryne brassicae) at Gkuleshor, Baitadi, Nepal
}

\author{
Narendra Bahadur Singh ${ }^{1}$, Santoshi Dhungana ${ }^{2}$, Srijana Adhikari², Dipesh Chapagain ${ }^{2}$, Nawaraj Ghimire², \\ Sarad DC ${ }^{2}$ \\ ${ }^{1}$ Institute of Agriculture and Animal Science, Gauradaha Agriculture Campus, Tribhuvan University, Nepal \\ ${ }^{2}$ Gokuleshwor Agriculture and Animal Science College, Tribhuvan University, Nepal \\ Corresponding author's email: iaassingh2010@gmail.com
}

Received on: 14 July 2019, Revised on: 23 September 2019, Accepted on: 5 October 2019

\begin{abstract}
Field screening of seven cultivars of cabbage namely: Green Crown, Green Top, Green Coronet, Pioneer, Nepa Round, Copenhagen Market and Golden Acre were carried out against cabbage butterfly (Pieris brassicae) and cabbage aphid (Brevicoryne brassicae) at the research farm of entomology section, Gokuleshwor Agriculture and Animal Science College, Baitadi in RCBD design from October 2017 to February 2018. Five plants were tagged randomly after transplanting in field excluding border plants in each plot. Data were collected for the population dynamics of cabbage butterfly larvae and cabbage aphid on weekly basis. None of the seven cultivars were found resistant to cabbage butterfly and cabbage aphid, however their population density varied on tested cultivars. Cabbage butterfly population was recorded the highest on the cultivar Pioneer (22.88 larvae/plant) and the lowest on the cultivar Copenhagen Market (10.06 larvae/plant), and other cultivars were of intermediate types. Similarly, the population density of aphid ranged from 36.70 to 105.58 aphids/leaf. The highest population density of aphid was recorded on cultivar Green Crown (105.58 aphids/leaf) and the lowest on cultivar Copenhagen Market (39.82 aphids/leaf. From the results, Copenhagen Market proved to be the best against both cabbage butterfly and cabbage aphids.
\end{abstract}

Keywords: : Aphid, Cabbage, Cabbage butterfly, Infestation, Population dynamics.

\section{Introduction}

Cabbage is a major winter vegetable crop belonging to the family Cruciferae. Among cole crops, cabbage is very attractive vegetable due to its nutritional importance. In Nepal, cabbage is a winter crop and its demand in the market is increasing but the main problem are damaging insect pests, which sometimes cause complete failure of the crop. The common insect pests of cabbage in Nepal are cabbage aphid (sucking type), cabbage butterfly, cabbage semi looper, diamond back moth, Flea beetle, grasshopper, field cricket etc. Out of them, cabbage butterfly and cabbage aphids have been considered the most destructive pests (Mahammad et. al., 2004). Insect pest infestation level is also dependent in the variety. Some variety is resistant to insect pest while others are not. It is also dependent on the growing time, temperature and the relative humidity. High population density of insect pests occurs on susceptible host type with favorable environment (high temperature along with available moisture).

Copyright (C) 2020 Nepal Horticulture Society. This article is licensed under Creative Commons Attribution 4.0 International License. This permits unrestricted use, distribution and reproduction in any medium provided the original work is properly cited 
The population dynamics is the aspect of population ecology dealing with factors affecting changes in population densities. Population may contain individual of different ages and its size (density) is likely to change over time, growing or shrinking according to the reproductive success of its member (Duchovskiene, 2005). Thus, population dynamics of insect pest if cross economic injury level from general equilibrium level then crop suffers from pest attack and farmers are in loss. The variety of cabbage commonly available in Nepal are: Golden Acre, Copenhagen Market, Green Coronet, Green Stone, Snow Queen, Snow King, Nepa Round, Green Top, and Green Crown. This study was carried out to monitor number of insects' pests on selected cultivars and identify the resistance and susceptible cultivar of cabbage to the insect pest under study.

\section{Methodology}

The research was carried out at the research farm of Entomology section, Gokuleshwor Agriculture and Animal Science College, Gokuleshwor, Biatadi from October 2017 to February 2018. It is located at an elevation of 800 meter above the mean sea level and lies between $29035^{\prime}$ North latitude and $80025^{\prime}$ East longitude.

\section{Description of research site}

The field was previously planted with turmeric. The longitudinal layout was facing with east- west direction. The annual average rainfall of research site is $3.3 \mathrm{~mm}$ (Oct) $-139.0 \mathrm{~mm}$ (June) with average humidity ranges from $49.3 \%$ to $85.2 \%$. The average annual minimum and maximum temperature is $14.25 \mathrm{oC}$ and $28.460 \mathrm{C}$. The soil test was also conducted initially to determine its $\mathrm{pH}$ and major nutrients which is presented in table 1 .

\begin{tabular}{|c|c|c|c|c|}
\hline \multicolumn{5}{|c|}{ Table 1. Soil condition at research field. } \\
\hline Soil pH & Organic matter $(\%)$ & Nitrogen $\mathbf{( \% )}$ & Phosphorus (kg/ha) & Potassium (kg/ha) \\
\hline 6 (acidic) & 2.4 (low) & 0.12 (medium) & 64.12 (medium) & 226.83 (medium) \\
\hline
\end{tabular}

\section{Nursery and land preparation}

Nursery bed was prepared and treated with formalin 2 $\mathrm{ml}$ per litre of water. Different varieties of cabbage were sown in the nursery on the second week of October. At the time of sowing Trichoderma viridae was applied at a rate of $5 \mathrm{gm}$ per litre of water for the control of fungal diseases like damping off. After 4-week, healthy seedlings of cabbage were transplanted on the main field. Field was prepared with fertilizers@12:9:4 $\mathrm{kg}$ NPK and 5-ton FYM per ropani. All inputs such as fertilizer application, irrigation, hoeing and others agronomic practices remained same for all cultivars.

\section{Treatments and experimental design}

Seven cultivars of cabbage namely: Green Crown, Green Top, Green Coronet, Pioneer, Nepa Round, Copenhagen Market and Golden Acre were selected which are adaptable to the research site. The experiment was carried out in Randomized Complete Block Design (RCBD) with three replications. The total area of experimental field was $144 \mathrm{~m} 2$ and it was divided into three main blocks representing replications and each main block was sub divided into seven small plots each of size $2 \mathrm{~m} \times 2 \mathrm{~m}$. The distance between each sub-plot was $0.5 \mathrm{~m}$ and each replication were separated by $1 \mathrm{~m}$. Row to row distance was kept $50 \mathrm{~cm}$ and plant to plant distance $40 \mathrm{~cm}$.

\section{Data observation and analysis}

Five plants were tagged randomly after transplanting in such a way that border plants were excluded from each treatment. Data were collected for the population dynamics of cabbage butterfly and cabbage aphid on weekly basis. The population density of cabbage butterfly was recorded on the basis of number of larvae per plant. All the open leaves and open heads of the selected plants were observed thoroughly and the number of larvae were recorded. Actual number of adult aphids was counted on both sides of the leaves of selected plants and recorded. The observed data were entered in Excel sheet and analyzed with the help of statistic tool R-Studio. The number of insects was compared among treatments following the single factor analysis of variance (ANOVA) and significant mean differences were compared with Duncan's multiple range test (0.05 level).

\section{Results}

Population dynamics of the cabbage butterfly and cabbage aphids on seven cabbage cultivars namely: Green Crown, Green Top, Green Coronet, Pioneer, Nepa Round, Copenhagen Market and Golden Acre were recorded at weekly interval throughout the season are presented in Tables 2 and 3 . 


\begin{tabular}{|l|l|l|l|l|l|l|l|l|}
\hline \multicolumn{6}{|c|}{ Table2. Cabbage butterfly (Pieris brassicae) larvae per plant on seven cultivars of cabbage on respective dates. } \\
\hline Cultivars & 15 DAT & 22 DAT & 29 DAT & 36 DAT & 43 DAT & 50 DAT & 57 DAT & Average \\
\hline Green Crown & $26.53 \mathrm{a}$ & $49.67 \mathrm{a}$ & $14.27 \mathrm{c}$ & $2.93 \mathrm{c}$ & $8.70 \mathrm{~cd}$ & $2.50 \mathrm{e}$ & $1.37 \mathrm{~d}$ & $15.14 \mathrm{~cd}$ \\
\hline Green Top & $11.27 \mathrm{c}$ & $37.27 \mathrm{~b}$ & $18.57 \mathrm{~b} \mathrm{c}$ & $5.33 \mathrm{c}$ & $4.50 \mathrm{e}$ & $6.03 \mathrm{~d}$ & $3.77 \mathrm{c}$ & $12.39 \mathrm{de}$ \\
\hline Green Coronet & $9.43 \mathrm{~cd}$ & $45.80 \mathrm{a}$ & $19.03 \mathrm{~b}$ & $15.93 \mathrm{~b}$ & $6.27 \mathrm{de}$ & $11.03 \mathrm{c}$ & $6.67 \mathrm{~b}$ & $16.31 \mathrm{~b} \mathrm{c}$ \\
\hline Pioneer & $6.70 \mathrm{~d}$ & $42.67 \mathrm{a} \mathrm{b}$ & $51.47 \mathrm{a}$ & $24.00 \mathrm{a}$ & $9.20 \mathrm{~cd}$ & $20.67 \mathrm{a}$ & $5.47 \mathrm{~b} \mathrm{c}$ & $22.88 \mathrm{a}$ \\
\hline NepaRound & $19.90 \mathrm{~b}$ & $46.77 \mathrm{a}$ & $17.33 \mathrm{~b} \mathrm{c}$ & $5.87 \mathrm{c}$ & $19.10 \mathrm{a}$ & $15.03 \mathrm{~b}$ & $11.10 \mathrm{a}$ & $19.30 \mathrm{~b}$ \\
\hline Copenhagen Market & $7.63 \mathrm{~d}$ & $21.15 \mathrm{c}$ & $14.97 \mathrm{c}$ & $3.40 \mathrm{c}$ & $11.30 \mathrm{c}$ & $10.47 \mathrm{c}$ & $1.53 \mathrm{~d}$ & $10.06 \mathrm{e}$ \\
\hline Golden Acre & $19.00 \mathrm{~b}$ & $37.10 \mathrm{~b}$ & $31.67 \mathrm{~b}$ & $20.77 \mathrm{a} \mathrm{b}$ & $15.70 \mathrm{~b}$ & $2.97 \mathrm{e}$ & $1.40 \mathrm{~d}$ & $18.37 \mathrm{~b}$ \\
\hline GM & 14.35 & 40.06 & 23.9 & 11.18 & 10.68 & 9.81 & 4.47 & 16.35 \\
\hline LSD 0.05 & $3.18 * * *$ & $11.26^{* *}$ & $15.96^{* *}$ & $7.89^{* * *}$ & $3.21^{* * *}$ & $1.51^{* * *}$ & $1.939^{* *}$ & $3.18^{* * *}$ \\
\hline MSE & 3.190 & 7.39 & 80.51 & 19.65 & 3.26 & 0.72 & 1.188 & 3.19 \\
\hline CV $(\%)$ & 12.45 & 10.37 & 37.54 & 39.67 & 16.91 & 8.65 & 24.38 & 10.93 \\
\hline
\end{tabular}

DAT: Days after transplanting; GM: Grand Mean, LSD: Least significant difference, MSE: Standard error of mean, $\mathrm{CV}$ : Coefficient of variance; Mean values in each column with the same common small letters are not significantly different by LDS value.

The population density of cabbage butterfly (Pieris brassicae) on different date was recorded on the basis of number of larvae per plant on randomly selected plants throughout the season is presented in Table 2. The table shows significant population density of cabbage butterfly per plant recorded in different dates. The cabbage butterfly infestation started at the last week of November with an average population density of $26.53,11.27,9.43$, 6.70, 19.90, 7.63 and 19.00 on cultivars Green Crown, Green Top, Green Coronet, Pioneer, Nepa Round, Copenhagen Market and Golden Acre, respectively and increased gradually. It remained at the peak during second week of December with an average of 49.67, $37.27,45.80,42.67,46.77,21.51$ and 37.10 larvae per plant on cultivars Green Crown, Green Top, Green

Coronet, Pioneer, Nepa Round, Copenhagen Market and Golden Acre, respectively. Population density of the pest declined gradually till the end of January and reaches to an average population density $1.37,3.77$, $6.67,5.47,11.10,1.53$ and 1.40 larvae/plant. The result of cabbage butterfly incidence is supported by Qureshi (1969). Cultivar Copenhagen Market showed the best performance against cabbage butterfly by attracting the least average population (10.06 larvae/plant). Cultivar Green Top (12.39 larvae/plant) was next in performance against cabbage butterfly followed by Green Crown (15.14) and Green Coronet (16.31) while cultivar Pioneer showed the highest population (22.88 larvae/plant). The result is also similar to that of Martin et al. (1992) in different cultivars of cauliflower. They reported that leaf damage by cabbage butterfly in cultivars Snowball and

Snowdrift was highly significant.

\begin{tabular}{|l|l|l|l|l|l|l|l|l|}
\hline \multicolumn{6}{|l|}{ Table3. Number of cabbage aphids (Brevicoryne brassicae) per leaf on seven cultivars of cabbage on respective dates. } \\
\hline Cultivars & 15 DAT & 22 DAT & 29 DAT & 36 DAT & 43 DAT & 50 DAT & 57 DAT & Average \\
\hline Green Crown & $37.90 \mathrm{a}$ & $203.33 \mathrm{a}$ & $147.33 \mathrm{a}$ & $139.40 \mathrm{~b}$ & $111.40 \mathrm{~b}$ & $80.33 \mathrm{a}$ & $19.33 \mathrm{a}$ & $105.58 \mathrm{a}$ \\
\hline Green Top & $20.50 \mathrm{~b}$ & $72.90 \mathrm{~d}$ & $51.23 \mathrm{~b}$ & $48.77 \mathrm{~d}$ & $50.00 \mathrm{c}$ & $29.70 \mathrm{c}$ & $5.63 \mathrm{~b}$ & $39.82 \mathrm{~d}$ \\
\hline Green Coronet & $8.23 \mathrm{c}$ & $103.67 \mathrm{c}$ & $51.47 \mathrm{~b}$ & $87.33 \mathrm{c}$ & $72.13 \mathrm{c}$ & $30.33 \mathrm{c}$ & $19.73 \mathrm{a}$ & $53.27 \mathrm{~b}$ \\
\hline Pioneer & $7.20 \mathrm{c}$ & $179.60 \mathrm{~b}$ & $139.70 \mathrm{a}$ & $152.67 \mathrm{~b}$ & $196.40 \mathrm{a}$ & $29.47 \mathrm{c}$ & $20.13 \mathrm{a}$ & $103.59 \mathrm{a}$ \\
\hline NepaRound & $23.40 \mathrm{~b}$ & $84.23 \mathrm{~cd}$ & $34.23 \mathrm{c}$ & $49.67 \mathrm{~d}$ & $51.57 \mathrm{c}$ & $61.40 \mathrm{ab}$ & $26.33 \mathrm{a}$ & $47.26 \mathrm{c}$ \\
\hline Copenhagen Market & $4.97 \mathrm{c}$ & $13.67 \mathrm{e}$ & $18.80 \mathrm{~d}$ & $34.73 \mathrm{~d}$ & $96.33 \mathrm{~b}$ & $81.07 \mathrm{a}$ & $7.37 \mathrm{~b}$ & $36.70 \mathrm{~d}$ \\
\hline Golden Acre & $25.67 \mathrm{~b}$ & $199.13 \mathrm{a} \mathrm{b}$ & $152.23 \mathrm{a}$ & $178.93 \mathrm{a}$ & $100.53 \mathrm{~b}$ & $42.33 \mathrm{bc}$ & $25.60 \mathrm{a}$ & $103.49 \mathrm{a}$ \\
\hline GM & 18.27 & 122.36 & 85.84 & 98.79 & 96.91 & 50.66 & 17.73 & 69.95 \\
\hline LSD 0.05 & $7.094^{* *}$ & $22.99^{* * *}$ & $12.75^{* *}$ & $18.44^{* *}$ & $22.30^{* *}$ & $22.15^{* *}$ & $10.69^{* *}$ & $5.85^{* * *}$ \\
\hline MSE & 15.902 & 167.03 & 51.35 & 107.47 & 157.14 & 155.11 & 36.13 & 10.82 \\
\hline CV $(\%)$ & 21.83 & 10.56 & 8.43 & 10.49 & 12.94 & 24.58 & 33.89 & 4.70 \\
\hline
\end{tabular}

DAT: Days after transplanting; GM: Grand mean, LSD: Least Significant Difference, MSE: Mean sum of square, CV: 
Coefficient of variance; Mean values in each column with the same common small letters are not significantly different by LSD value.

The population density of cabbage aphids (Brevicoryne brassicae) recorded on the basis of number of adult aphids per leaf on randomly selected plants throughout the cropping season is presented in Table 3. The results showed that, Aphids infestation started at the last week of November (15 DAT) with an average population density of $37.90,20.50,8.23,7.20,23.40,4.97$ and 25.67 aphids/leaf on cultivars Green Crown, Green Top, Green Coronet, Pioneer, Nepa Round, Copenhagen Market and Golden Acre, respectively and increased gradually from the first week of December to midDecember. It remained at the peak on mid-December with an average population density of 203.33, 72.90, 103.67, 179.67, 84.23, 13.67 and 199.13 aphids/leaf on cultivars Green Crown, Green Top, Green Coronet, Pioneer, Nepa Round, Copenhagen Market and Golden Acre, respectively. Then population declined with the onset of low temperatures and the crop progressed towards maturity at the end of January, with an average population density of $19.33,5.63,19.73,20.13$, 26.33, 7.37 and 25.60 aphids/leaf. Results showed that cultivar Copenhagen Market performed the best against cabbage aphids with an average 36.70 aphids/ leaf throughout the cropping seasons. Green Top was the next in performance against aphids while cultivars Green Crown and Pioneer developed the highest aphid population.

\section{Discussions}

Heritable characters possessed by the plant reduces the pest infestation by the means of antibiosis and tolerance. Antibiosis refers to adverse effects on life history of an insect due to feeding on a resistant host. The effects may be death, reduced growth, low weight, reduced fecundity, extended life cycle and abnormal behavior. In this study, choice and non-choice leaf feeding allowed to discriminate among varieties according to their environmental effect and survival of cabbage butterfly. This was previously identified by Cartea et al., (2009b) on 'Coraz on de buey' and BRS0535 varieties. It has been reported that shorter development times and higher rates of reproduction with low insect mortality rates on a host indicate low levels of antibiosis, whereas higher larval mortality rates and longer development times indicate greater host antibiosis (Dosdall \& Ulmer, 2004; Hasan \& Ansari, 2011).
The population density of Cabbage butterfly larvae per plant on different cultivars of cabbage is presented in table 2 is supported by Mohammad et al., (2004). They conducted the research on population dynamics of cabbage butterfly and cabbage aphids on five cultivars of cauliflower at Peshawar. They reported that the cabbage butterfly infestation started at the last week of October with a highest population density (73.33) on Tropical cultivar and no any insect was reported on Meigettsal cultivar and increases gradually. It remains peak during first week of November and declined gradually till the end of December with a highest population density of cabbage butterfly larvae (5.67) on snowball whereas remaining all cultivars becomes free-from cabbage butterfly. These results also in agreement with that of Matin et al., (1992). They reported that the infestation rate of cabbage butterfly in varieties snowball and snowdrift was highly significant.

Munthali (2009) conducted the research on different nine varieties of cabbage resistance to cabbage aphid in Africa under greenhouse condition. He reported that the Cabbage aphids caused $85 \%$ leaf damage on variety Drumhead which is most susceptible variety against cabbage aphids, and caused only 30.9 and 44.6 $\%$ on Grandslam and Copenhagen Market, respectively which are considered as most resistance varieties of cabbage. Grandslam had the lowest number of aphids per leaf, showing the antibiosis mechanism of resistance to cabbage aphids. Although Copenhagen Market was resistant to cabbage aphid damage, it had the greatest abundance of aphids per leaf, showing that it used the tolerance resistance mechanism against cabbage aphids.

Result presented in table 3 are in conformity with Atwal (1976), who reported that the aphids remained most abundant during November- December in autumn season and cloudy and cold weather was very much favorable. These slight differences might be due to climatic condition of the concerned regions or due to the presence of natural enemies in the field. As reported by Hagen and Bosch (1968) ladybird beetle and lacewings larvae and adults feed on aphids. Similarly, it also tallied with the finding of Weber et al. (1991), who reported the abundance aphid species Brevicoryne brassicae in autumn near crop harvest. Sain et. al. (2017) reported that, the population of cabbage aphids appeared in first week of November. It was gradually increased and became maximum during third week of December (99.5 aphids/leaf) when the temperature 
and relative humidity ranged from $20.57^{\circ} \mathrm{C}$ to $11.21^{\circ} \mathrm{C}$ (mean $15.89^{\circ} \mathrm{C}$ ) and 73.71 to 37.42 per cent $(55.56 \%$ ) respectively. However, lowest population was recorded (7.11 aphids/leaf) when the temperature ranged from $20.92^{\circ} \mathrm{C}$ to $8.21^{\circ} \mathrm{C}$ and relative humidity 52.64 percent.

\section{Conclusions}

No cultivars were observed free from pest infestation, but cultivars varied in degree of intensity of pest population. Cabbage butterfly population density was recorded the highest on Pioneer variety and the lowest on Copenhagen Market. While, cabbage aphid developed to its highest population density on Green Crown and the lowest on Copenhagen Market. Cultivar Copenhagen Market is considered to be the best and highly preferred variety against cabbage butterfly and cabbage aphids.

\section{Aknowlwdgements}

We are thankful to Gokuleshwor Agriculture and Animal Science College, Department of Horticulture and Plant Protection, Institute of Agriculture and Animal Science, Tribhuvan University, Nepal.

\section{References}

Atwal, A.S. 1976. Agricultural pests of India and South East Asia. Kalyani Publ., New D e 1 h i , India. pp:21-29.

Cartea, M.E., P. Soengas, A. Ordas and P. Velasco. 2009b. Resistance of kale varieties to attack by Mamestra brassicae. Agricultural and Forest Entomology, 11, 153-160.

Dosdall, L.M. and B.J. Ulmer. 2004. Feeding, development, and oviposition of bertha armyworm (Lepidoptera: Noctuidae) on different host plant species. Environmental Entomology, 33, 756-764

Duchovskiene, L. 2005. Seasonal abundance dynamic of cabbage aphid, Brevicorynebrassicaein differently fertilized white cabbage. Scientific Works of the Lithuanian Institute of Horticulture and Lithuanian University of Agriculture. Sodininkyste IRDarzininkyste24(4); 163-171.

Hagen, K.S. and R. van den Bosch, 1968. Impact of pathogens, parasites and predators on aphids, Ann. Rev. Entomol., 13: 325-384.

Hasan, F., M.S. Ansari. 2011. Population growth of Pieris brassicae (L.) (Lepidoptera: Pieridae) on different cole crops under laboratory conditions. Journal of Pest Science, 84, 179-186.

Matin, M.A., S.A. Saghir and M.A. Rafi, 1992. Quantitative relationship between Pieris brassicae population and damage in cauliflower. Philippine Entomol., 8: 1182-1188.

Mohammad, Y., N. Mohammad, R. Abdur and M. Shah. 2004. Population dynamics of cabbage butterfly (Pieris brassicae) and cabbage aphids (Brevicoryne brassicae) on five cultivars of cauliflower at Peshawar. Assian Journal of Plant Science. 3(3): 391-393.

Munthali, D.C. 2009. Evaluation of Cabbage Varieties for Resistance to the Cabbage Aphid," African Entomology 17(1), 1-7.

Qureshi, N.H. 1969. Insect pests of cabbage and biology of cabbage butterfly. M.Sc. Thesis, College of Agriculture, University of Peshawar, Pakistan.

Sain, Y., R. Singh and S. Kumar. 2017. Seasonal incidence of mustard aphid, Lipaphis erysimi (Kalt.) (Homoptera: Aphididae) in Meerut region, Uttar Pradesh. Journal of Entomology and Zoology Studies, 5(6): 314-317.

Weber, D.C., M. Baefsky and J.C. Herr. 1991. Aphids on California winter cauliflower. South-Western Entomol., 16: 251-260. 